\title{
O LAQUES E O PROTÁGORAS SEGUNDO VLASTOS
}

\author{
João Paulo de Oliveira Teixeira* * Universidade \\ Federal de Minas \\ Gerais.
}

RESUMO: Este texto tem como objetivo uma análise crítica do artigo de Vlastos "The Protagoras and the Laches", e de sua tese central acerca da anterioridade do Protágoras com relação ao Laques. Para isso, Vlastos defende a existência de uma distinção entre saber moral e técnico no Laques, distinção que estaria ausente no Protágoras, e interpreta o Laques como uma refutação da tese da unidade das virtudes apresentada no Protágoras. Pretende-se demonstrar que Vlastos retira suas supostas evidências textuais dos seus respectivos contextos, de modo a melhor servirem de base para sua interpretação. No entanto, as passagens escolhidas por Vlastos, quando analisadas no interior de seus contextos, não parecem permitir nenhuma das inferências do comentador.

PALAVRAS-CHAVE: Laques; Protágoras; unidade das virtudes; saber técnico; saber moral.

\section{LACHES AND PROTAGORAS ACCORDING TO VLASTOS}

\begin{abstract}
This text aims to analyze and criticize the Vlastos' paper "The Protagoras and the Laches" and its central thesis about Protagoras' anteriority with relation to Laches. To this end, Vlastos defends the existence of a distinction amongst moral knowledge and technical knowledge in Laches, distinction that is absent in the Protagoras, and he interprets Laches as a refutation of the thesis of virtue's unity presented in Protagoras. This text claims that Vlastos removes his supposed textual evidences from their respective contexts, in the interest of the passages to be more useful for his interpretation, however, the passages chosen by Vlastos, if analyzed in their context, don't allow the inferences that the commentator did.
\end{abstract}

KEYWORDS: Laches; Protagoras; moral knowledge; technical knowledge; virtue's unity.

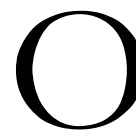

objetivo deste estudo é analisar criticamente a tese apresentada por Vlastos no artigo "The Protagoras and the Laches" sobre a anterioridade do Protágoras em relação ao

Laques. 
Considero esta questão importante, pois Vlastos parte da tese da anterioridade do Protágoras para afirmar que a tese socrática da unidade das virtudes já havia sido superada no momento de escrita do Laques.

Vlastos defende a anterioridade do Protágoras com base em dois argumentos: 1) haveria no Laques uma distinção entre saber moral e saber técnico que não existiria no Protágoras; 2) o Laques seria uma refutação da principal tese do Protágoras, a saber, a tese da unidade das virtudes.

Comecemos pelo primeiro argumento. Vlastos contrapõe a passagem do Protágoras 349e-350c com Laques 192e-193c. Segundo Vlastos, Platão em Prt. 349e-350c defende a seguinte tese: quanto mais conhecimento, mais coragem. O tipo de conhecimento não é especificado, pois Platão ainda não os havia diferenciado. Mas os exemplos que Sócrates dá nessa passagem, saber mergulhar, cavalgar ou ser um escudeiro (peltastés), indicam que ele pensava aqui em saberes técnicos.

Já em Laques 192e-193c, Platão defenderia a tese oposta. Segundo Vlastos, primeiramente o diálogo faz a distinção entre saberes grandes e pequenos. Vlastos aproveitase de passagens da Apologia e do Criton para fazer equivaler saberes grandes com os saberes morais e os pequenos com os técnicos. Depois demonstra que os saberes técnicos não implicam coragem, dando para isso quase os mesmos exemplos que os do diálogo Protágoras: saber cavalgar, atirar flechas, lutar com uma funda, mergulhar num poço. $\mathrm{O}$ uso dos mesmos exemplos seria uma maneira de Platão remeter ao texto de Protágoras e assim corrigir o erro lá cometido devido à falta de diferenciação entre saberes grandes e pequenos. Assim sendo, o Laques seria uma correção de Platão às teorias socráticas.

Observo, porém, que as passagens citadas como evidências textuais por Vlastos são problemáticas e que Vlastos recorta-as de seus contextos para dar suporte à sua interpretação.

De fato, em Prt.349e-350c, Sócrates afirma que quanto mais conhecimento, - sem explicitar se se trata de um conhecimento técnico ou moral - mais coragem. Mas ele assim o faz apenas para ser refutado em seguida por Protágoras (350c-351b). É possível questionar se a resposta de Protágoras é mesmo uma refutação ou não, mas o fato é que Sócrates não questiona, aceita-a e retoma a discussão usando um argumento inteiramente novo. Não há nenhum elemento no diálogo que nos permite pensar que tal passagem é uma falsa refutação. Assim sendo, creio impossível interpretar a passagem inteira de Prt. 349e-351b como uma defesa de que quanto mais conhecimento, independentemente se técnico ou moral, mais coragem.

Já ao utilizar a passagem La.192e-193c, Vlastos ignora a conclusão do argumento em 193c-d. Essa passagem é ainda mais complexa que a do Protágoras. Podemos dividi-la em três partes.

$\mathrm{Na}$ primeira parte temos o estabelecimento da diferença entre saberes das coisas grandes e saberes das coisas pequenas. Sócrates dá exemplo de saberes das coisas pequenas aliadas à persistência e pergunta se tais exemplos seriam exemplos de coragem. Laques nega. Cito a passagem em questão: 
Sócrates - Vejamos, então, quando ela [a perseverança] está unida à razão: apenas em alguns casos, ou em todos, tanto nas coisas grandes como nas pequenas? Por exemplo: se alguém persevera em gastar com parcimônia o seu dinheiro, sabendo que com esses gastos acabará ganhando mais, dás a isso o nome de coragem?

Laques - Eu não, por Zeus!

Sócrates - Ou então, no caso de um médico a quem peça o filho, ou qualquer enfermo com pneumonia, que lhe dê de beber ou de comer, e que não se deixe dobrar ante a insistência, mas persista na recusa: coragem é isso?

Laques - Está mais longe, ainda, de ser coragem. ${ }^{1}$

Algumas diferenças podem ser notadas entre essa primeira parte e a parte seguinte. Primeiramente a pergunta muda. Não se trata mais de saber se uma persistência aliada a certo conhecimento é corajosa ou não. A pergunta aqui é: quem é o mais corajoso: o conhecedor de certo tipo de saber, ou o ignorante? Isso não é sem importância, pois se continuássemos com o mesmo tipo de questão, ou seja, se Sócrates perguntasse se a coragem é certa persistência para combater quando seu conhecimento indica que tal é necessário, a resposta de Laques provavelmente seria outra. Também devemos notar que seria estranho se o tipo de questão dessa segunda parte fosse feito com os primeiros exemplos, ou seja, se Sócrates perguntasse a Laques: "quem é mais corajoso: alguém que persiste em economizar sabendo que com isso ganhará mais no futuro ou aquele que persiste economizar mesmo sem saber se tal, no futuro, lhe dará mais dinheiro?" Este tipo de questão seria estranha, pois sabemos que a coragem não estaria relacionada com nenhum dos dois exemplos. Outra diferença: a resposta para as primeiras questões é óbvia, pois é claro que persistência para gastar com parcimônia não é um exemplo de coragem e ninguém diria o contrário, já o segundo caso é complicado, pois é possível defender a alternativa oposta, como o próprio Vlastos nos diz que Sócrates teria feito no Protágoras. Outro ponto importante é que os exemplos citados nessa parte, com a exceção da arte de mergulhar, são exemplos de artes militares e é algo duvidoso que Sócrates nomeasse as artes militares entre as artes pequenas com a aquiescência de dois generais provenientes de uma cultura guerreira como a da Grécia Antiga. Vlastos, porém, ignora essas distinções e toma essas duas passagens como um todo contínuo. Em seu artigo ele nos diz (tradução minha): "O que Sócrates agora quer saber é que tipo de conhecimento, isto, a coragem, teria de ser: 'Conhecimento em que? Em todas as coisas, sejam elas grandes ou pequenas?' Sócrates pergunta, e então continua citando caso atrás de caso de sábia persistência cuja sabedoria não nos dá nenhuma razão para chamá-la corajosa" ${ }^{2}$ e nesse ponto Vlastos cita de maneira indiferenciada os exemplos das passagens 192e-193a e 193a-c.

Cito agora a segunda parte dessa passagem:

\footnotetext{
${ }^{1}$ Laques 192e-193a.

${ }^{2}$ VLASTOS, 1994, p.109. A passagem citada por Vlastos nessa citação é do Laques 192e.
} 
Sócrates - E na guerra, o indivíduo persistente, que se dispõe a lutar depois de calcular prudentemente, por saber que não somente receberá ajuda dos companheiros, como terá de haver-se com inimigos inferiores e em menor número do que os que combatem ao seu lado, além de contar com a superioridade do terreno: um indivíduo nessas condições, que persistisse após tanta reflexão e tantos recursos, seria por ti considerado mais valente do que o antagonista das fileiras inimigas, que se decidisse a permanecer no seu posto de combate?

Laques - A meu ver, Sócrates, o das fileiras inimigas é o mais bravo.

Sócrates - Mas a sua perseverança é mais imprudente do que a do seu contrário.

Laques - Tens razão.

Sócrates - E o cavaleiro conhecedor da arte de bem cavalgar, que num combate de cavalaria se mostre persistente, não considerarias menos corajoso do que o que carecesse desse conhecimento?

Laques-É o que eu penso, também.

Sócrates - E o mesmo dirás do arqueiro, do lutador de funda, ou de qualquer outro, cuja persistência decorra de seus conhecimentos da matéria?

Laques - Perfeitamente.

Sócrates - E o indivíduo que se joga num poço sem ser forte na profissão de mergulhador e persiste em mergulhar, ou a arrostar qualquer perigo idêntico, não consideras mais corajoso do que o perito nessa matéria?

Laques - Quem poderia sustentar o contrário, Sócrates?

Sócrates - Ninguém, se pensar dessa maneira.

Laques - Pois é assim que eu penso. ${ }^{3}$

E por fim, a parte não analisada no artigo de Vlastos, e que é também a conclusão do argumento: se a coragem fosse uma audácia insensata e ignorante, ela seria algo vergonhoso e prejudicial. Ambos concordam que tal não pode ser o caso e, posteriormente (193e-194c), chamam a ajuda de Nícias. Eis a última parte:

Sócrates - No entanto, Laques, todos esses que se lançam desse modo nos perigos e neles persistem, são bem mais imprudentes do que os que fazem com o conhecimento das respectivas artes.

Laques-É muito certo.

Sócrates-Mas a persistência e a audácia insensata já se nos revelaram como vergonhosas e prejudiciais.

${ }^{3}$ Laques 193a-c. 
Laques - Perfeitamente.

Sócrates - E concordamos também que a coragem é algo belo.

Laques - Concordamos, realmente.

Sócrates - Agora, porém, afirmamos outra vez que a persistência vergonhosa e insensata é coragem.

Laques - Foi, de fato, o que fizemos.

Sócrates - E és de parecer que falamos com acerto?

Laques - Eu não, Sócrates, por Zeus! ${ }^{4}$

Quando analisamos a passagem toda, de 192e-193d, isto é, incluindo a conclusão ignorada por Vlastos, vemos que há dois tipos de interpretação possível:

1) Continuidade das passagens 192e-193a e 193a-c, e, assim, os saberes militares são um saber das coisas pequenas e, portanto, um saber técnico. Nesse caso, pela conclusão do argumento (193c-d), os saberes técnicos são sim necessários para a coragem (de outro modo transformaríamos a coragem em algo baixo). Se assim for, a coragem será persistência sábia, tanto nas coisas grandes quanto nas pequenas;

2) Descontinuidade dos momentos a e b acima, onde as artes militares seriam exemplos de sabedoria com as coisas grandes. Assim sendo, Sócrates primeiramente diferencia saberes grandes e pequenos (192e), depois pergunta se a coragem pode estar associada aos saberes das coisas pequenas (192e-193a), isto é, gastar dinheiro com cautela ou persistência no cumprimento de uma receita médica, chegando à conclusão de que tais saberes não são importantes para a definição da coragem. E, por fim, Platão investiga a persistência aliada aos saberes grandes (193a-193c), isto é, conhecimento sobre cavalaria, arco e flecha, mergulho, concluindo que tais saberes seriam importantes na definição de virtude. Nesse caso, não se pode dizer que a divisão entre saberes grandes e pequenos seja uma divisão entre saberes morais e técnicos, mas alguma outra divisão, talvez entre saberes envolvendo situações com risco de vida e saberes onde tal risco não exista.

Porém, seja como for, a verdade é que Sócrates não conclui nem nos dizendo que a coragem é persistência sábia tanto nas coisas pequenas quanto nas grandes, nem nos dizendo que a coragem é a persistência sábia com relação às coisas grandes, muito provavelmente porque a tese da coragem como persistência sábia tal como é posta até então é um tanto contra-intuitiva, como fica claro no exemplo do enfrentamento de um exército mais forte com um exército mais fraco, onde o exército mais forte é mais corajoso que o exército mais

\footnotetext{
${ }^{4}$ Laques $193 \mathrm{c}-\mathrm{d}$.
} 
fraco - basta radicalizar o exemplo para concluirmos que bater em uma velhinha é mais corajoso que bater "em alguém do seu tamanho".

Vlastos segue a primeira linha de interpretação, mas ignora a conclusão de Sócrates em 193c-d, ficando apenas com as palavras de Laques, como se essas fossem a conclusão do argumento. Agindo dessa maneira, Vlastos poderá dizer em seu artigo: "Exatamente os mesmo exemplos - mergulhadores experientes, cavaleiros, peltastas e arqueiros habilidosos - que são usados no Protágoras para sustentar a coragem superior daqueles que possuem um saber técnico são usados no Laques, como vimos, para estabelecer a tese contrária, isto é, que as pessoas que enfrentam o perigo mesmo sem ter experiência em mergulho ou cavalaria estão agindo com não menos coragem que aqueles que são experientes nessas técnicas enfrentando os mesmos perigos". ${ }^{5}$ Ressaltamos aqui a estranheza da situação, onde Platão nos dá exatamente os mesmos exemplos para exemplificar teses opostas sem em nenhum momento estabelecer uma discussão entre esses dois pontos de vista e argumentar por aquela que seria a tese que os exemplos verdadeiramente exemplificam (a estranheza não se dá pelo desleixo de Platão, que poderia futuramente causar interpretações equivocadas, mas antes pelo fato de o próprio Platão ter pensado que tais exemplos exemplificavam uma teoria e, depois, ter passado a crer que tais exemplos exemplificavam a teoria diametralmente oposta, e ainda assim não tivesse considerado necessário explicar as razões que o levaram a pensar diferentemente. Ao invés disso, Platão ofereceria os exemplos citados como se eles obviamente exemplificassem uma das teses). Creio, porém, que tais dificuldades sejam superadas, caso sigamos a primeira interpretação até o final e concluamos que $L a$. 192e-193d é semelhante à Prt. 349e-350c, isto é, que os saberes técnicos/militares têm alguma importância para a definição de coragem, ou então, sigamos a segunda linha interpretativa e concluamos que a distinção entre saberes grandes e pequenos não é uma distinção entre saberes técnicos e morais, como o quer Vlastos, e assim sendo, novamente, o Sócrates do Laques concordaria com o Sócrates do Protágoras (observamos ainda que, mesmo nessa segunda linha interpretativa, os saberes grandes são importantes para a definição de coragem e os saberes técnico/militares estão incluídos entre os saberes grandes e, portanto, são importantes para a definição de coragem).

Desse modo: 1) não é de modo algum claro que a distinção entre saberes grandes e pequenos em La.192e-193d corresponda à distinção entre saberes morais e técnicos; 2) o Sócrates (do) Laques e o Sócrates do Protágoras parecem defender a mesma tese: os saberes militares ajudam na compreensão da coragem; e 3) tanto no Protágoras quanto no Laques tal tese socrática é problematizada.

Além disso, devemos nos lembrar também que no Protágoras, Sócrates defende a unidade das virtudes e uma das consequências desta é que quem possui uma virtude possui todas as demais. Assim, quem fosse corajoso também seria sábio, justo e pio. Protágoras, porém, não concorda com isso e nos diz (Prt. 349d): "Encontrará muitos homens que são muito injustos, muito impiedosos, muito intemperantes, muito ignorantes e no entanto

\footnotetext{
${ }^{5}$ VLASTOS, 1994, p.117.
} 
excepcionalmente corajosos". Sócrates nega tal afirmação, tentando demonstrar ao longo do diálogo que a virtude é o conhecimento do bem e do mal e que cada virtude, a coragem inclusive, participa desse conhecimento.

Ora, Vlastos baseia a distinção platônica entre saber técnico e saber moral no final do Cármides, onde se contrapõe o conhecimento do conhecimento com o conhecimento do bem e do mal. O conhecimento do conhecimento seria um saber técnico, pois seria um saber fazer as coisas, enquanto o conhecimento do bem e do mal é um saber moral, que nos ensinaria o que é melhor para se fazer. Assim sendo, voltando agora ao Protágoras, ao definir a coragem como conhecimento do bem e do mal, Platão faz dela um saber moral, não técnico. Por essa razão, de um lado, não se justifica a afirmação de Vlastos segundo a qual no Protágoras a coragem seria um saber técnico, não moral. Por outro, justifica-se sim a dúvida de Vlastos: se a coragem é um saber moral, por que Sócrates nos fala de saberes técnicos que seriam necessários para a manifestação da coragem?

A questão é complexa e aqui apenas esboço uma possível resposta: os saberes técnicos seriam condições necessárias para a coragem. Sem tais saberes, a coragem se torna pura bravata, não protege ninguém, deixa de ser virtude e, consequentemente, deixa de ser coragem. É preciso primeiramente saber se defender (conhecimento técnico), para depois saber quando é melhor para nós nos defendermos (conhecimento moral). É justamente a necessidade desse saber moral, desse conhecimento do bem e do mal que faz com que estranhemos o exemplo puramente técnico do Laques, onde o exército mais forte é também o mais corajoso.

Passo agora ao segundo argumento de Vlastos em favor da precedência do Protágoras com relação ao Laques, isto é, sobre a possível refutação da tese da unidade das virtudes no Laques. Vlastos interpreta a última parte do Laques como uma refutação da definição de coragem como conhecimento do bem e do mal, pois tal nos levaria à tese da unidade das virtudes, quando, na realidade, a virtude seria divisível em partes distintas.

Para tal interpretação, Vlastos utiliza-se de dois argumentos: 1) é o próprio Sócrates que introduz e, posteriormente, relembra a premissa da coragem como apenas parte da virtude; 2) no diálogo Mênon, a teoria da unidade da virtude como identidade entre todas as partes da virtude é posta em cheque pela comparação entre a unidade da virtude e a unidade da figura.

Ao fim do Laques e da argumentação entre Nícias e Sócrates, Sócrates nos diz: “nesse caso não descobrimos o que seja a coragem" (199e). Porém, não nos é dito qual teria sido o erro da argumentação que nos teria levado ao fracasso da definição de coragem, se se trata da coragem como parte da virtude ou da coragem definida como conhecimento do bem e do mal. Ao fim do diálogo, Sócrates retoma a premissa já aceita no começo da discussão (a coragem é uma parte da virtude) e demonstra que tal premissa é contraditória com a conclusão do argumento que se apoia na definição da coragem como conhecimento do bem e do mal. Vlastos interpreta essa retomada como uma reafirmação da posição inicial e interpreta o fim do diálogo como uma refutação da definição da coragem como conhecimento do bem e do mal a partir da premissa da não unidade da virtude. 
Porém, defendo que Sócrates está apenas retomando a totalidade do argumento nesse momento do texto e evidenciando assim suas contradições, sem nos dizer qual seria o erro responsável por tais contradições, se seria a definição de coragem como conhecimento do bem e do mal ou se a falha está na premissa de que a coragem é apenas uma parte da virtude.

Num cenário hipotético, onde toda obra de Platão fosse perdida, com exceção do Laques, creio que seria impossível apontar qual o erro da argumentação na parte final desse diálogo, pois ele não nos dá elementos para dirimir a questão. Porém, mesmo nesse caso, poderíamos afirmar que não é possível ler o Laques como uma refutação da tese da unidade das virtudes, pois a tese da não unidade das virtudes é apenas afirmada, postulada, sem que Sócrates nos dê qualquer argumento explicito em favor dela. Ora, não seria uma refutação da tese da unidade das virtudes dizer simplesmente "esta tese é falsa, pois a coragem é uma parte da virtude". Isto seria apenas uma contraposição; para ser uma refutação seria necessário somar uma justificação a essa contraposição.

Voltemos agora à passagem La.190b-e, onde Sócrates e Laques definem o objeto da investigação. No momento precedente a esta passagem, a conversa girava em torno da virtude, porém, como Sócrates observa que tal tema seria muito trabalhoso de ser tratado filosoficamente, ele sugere um novo objeto de inverstigação: a coragem. Vejamos de perto a passagem em questão: La190c-d “- De início investiguemos apenas uma pequena parte [da virtude], para sabermos se estamos em condições de dizer o que ela [a virtude] seja; é de supor ( $\omega$ s tó દikós) que desse modo a investigação se nos torne mais fácil. - Sim, façamos assim mesmo, Sócrates, como o desejas. - Que parte então escolheremos da virtude? Terá de ser, evidentemente, aquela a que tende a disciplina da hoplomaquia, e que todo o mundo pensa ser a coragem, não é assim?”.

Aqui temos claramente a imagem de um Sócrates iniciando uma investigação filosófica sobre a coragem, inocentemente considerando que a coragem seja uma parte da virtude. Assim sendo, não se pode considerar que no Laques há (haja) uma refutação da tese da unidade da virtude, pois (1) não há esforço argumentativo e (2) a tese da não unidade das virtudes é uma mera suposição, uma hipótese a ser trabalhada.

Invertamos agora a ordem proposta por Vlastos. As peças se encaixam com muito mais facilidade. Temos no Laques um Sócrates que inicia sua investigação filosófica sobre a coragem partindo da seguinte suposição: "a coragem é uma parte da virtude". Esta investigação, porém, termina em contradição, pois conclui que a definição de coragem é a mesma que a definição para o todo da virtude, indicando assim uma unidade das virtudes. Assim sendo, o diálogo termina em aporia. Em seguida temos o Protágoras, onde a posição de partida do Laques não é só abandonada, como contradita. Procura-se no Protágoras pela unidade das virtudes e tal unidade é defendida por uma sequência de argumentos. Mais ainda, os diferentes tipos de virtude são afirmados como idênticos e a definição para a coragem aqui é a mesma que Nícias propõe no Laques, porém, naquele contexto ela não pôde ser aceita, dada a premissa da não unidade das virtudes. Já no Protágoras, é justamente a tese da unidade das virtudes que se deseja provar. Observa-se aqui, porém, que não desejamos interpretar o Protágoras como uma refutação do Laques, mas antes um desenvolvimento dos 
mesmos temas sobre uma outra base e uma demonstração da superioridade de tal base sobre aquela trabalhada no Laques.

Aqui podemos responder aos dois argumentos utilizados por Vlastos para defender a interpretação do Laques como uma refutação da definição de coragem do Protágoras. Primeiramente, o fato de ter sido o próprio Sócrates que estabeleceu a premissa da coragem como parte da virtude não prova nada, uma vez que tal premissa é posta pelo próprio Sócrates como suposição verossímil a ser testada pela argumentação. Quanto ao segundo argumento - e não discutirei aqui a tese da unidade das virtudes conforme exposta no Mênon -, ainda que seja verdade que ele se oponha à tese da unidade das virtudes apresentada no Protágoras, isso obviamente não nos auxilia em nada sobre qual a posição do Laques nessa questão, se ao lado do Protágoras ou do Mênon.

Prefiro, portanto, a interpretação de C. Kahn sobre essa questão. Para este estudioso, o Laques é um diálogo onde um método é testado (analisar cada virtude em separado) e se mostra falho justamente porque a correta definição de cada parte da virtude é igual a toda parte da virtude. Assim sendo, tanto o Laques, como o Cármides, e o Eutífron são diálogos preparatórios para a tese da unidade das virtudes a ser apresentada de modo mais completo no Protágoras e no Mênon.

Para concluir, digo que a posição de Vlastos nessa questão sobre a anterioridade do Protágoras, parece-me ter sido mais influenciada por sua resistência à tese da unidade das virtudes que pela força de suas supostas evidências textuais. Um bom exemplo disso é o seu artigo "The unity of the virtue in the Protagoras", onde ele demonstra que em tal diálogo há duas formulações da tese da unidade das virtudes: 1) unidade das virtudes como identidade e 2) unidade da virtude como dupla implicação. Vlastos escolhe como a melhor formulação a segunda, pois entende que a primeira é falsa e sem sentido. Porém, se Platão formula sua tese dessas duas maneiras, parece-me claro que a primeira é a principal formulação, pois é mais forte e implica a segunda - se a coragem é idêntica à justiça, então, necessariamente, aquele que for corajoso será também justo. É justamente por tentar evitar essa tese mais forte da unidade das virtudes, tese esta que Vlastos não pode negar que esteja formulada no Protágoras, que ele tenta inverter a ordem cronológica dos dois diálogos, tentando transformar assim a tese da unidade das virtudes apenas numa primeira tese de Sócrates e Platão, tese ainda mal formulada e imatura, que logo em seguida será descartada. Porém, caso observemos a tese da unidade das virtudes de modo neutro, a argumentação de Vlastos se mostra pouco convincente.

\section{REFERÊNCIAS}

PLATÃO. Diálogos: Critão - Menão, Hípias Maior e outros. Tradução de Carlos Alberto Nunes. Belém: EDUFPA, 1980

PLATÃO. Protágoras. Tradução, introdução e notas de Eleazar Magalhães Teixeira. Fortaleza: UFC, 1986.

VLASTOS, G. The Protagoras and the Laques. In: . Socratic studies. Cambridge: Cambridge University Press, 1994. p. 109-126. 